\title{
Effects of Fin Arrangements on Thermal Hydraulic Performance of Supercritical Nitrogen in Printed Circuit Heat Exchanger
}

\author{
Shan Yang, Zhongchao Zhao *, Yong Zhang, Zhengchao Chen and Min Yang
}

Zhang, Y.; Chen, Z.; Yang, M.

Effects of Fin Arrangements on

Thermal Hydraulic Performance of Supercritical Nitrogen in Printed Circuit Heat Exchanger. Processes 2021, 9, 861. https://doi.org/ $10.3390 /$ pr9050861

Academic Editor: Paolo Blecich

Received: 18 March 2021

Accepted: 8 May 2021

Published: 13 May 2021

Publisher's Note: MDPI stays neutral with regard to jurisdictional claims in published maps and institutional affiliations.

Copyright: (C) 2021 by the authors. Licensee MDPI, Basel, Switzerland. This article is an open access article distributed under the terms and conditions of the Creative Commons Attribution (CC BY) license (https:// creativecommons.org/licenses/by/ $4.0 /)$.
School of Energy and Power, Jiangsu University of Science and Technology, Zhenjiang 212000, China; shanyang33@stu.just.edu.cn (S.Y.); yongzhang@stu.just.edu.cn (Y.Z.); zhengchaochen44@stu.just.edu.cn (Z.C.); yangmin@stu.just.edu.cn (M.Y.)

* Correspondence: zhongchaozhao@just.edu.cn; Tel.: +86-0511-8449-3050

Abstract: The printed circuit heat exchanger (PCHE) with discontinuous fins is a novel type of compact and highly efficient plate heat exchanger, which has superior thermal hydraulic performance. The morphology and characteristics of the flow channel greatly affect the performance of the PCHE. The discontinuous airfoil fins are used in PCHE channel design because they can affect the flow and heat transfer by increasing the heat transfer area and the disturbance in the channel. In this paper, the effects of different staggered distance $\left(\mathrm{L}_{\mathrm{s}}\right)$ and transverse distance $\left(\mathrm{L}_{\mathrm{v}}\right)$ of airfoil fin arrangements on the heat transfer and flow of supercritical nitrogen in the PCHE are numerically simulated using ANSYS Fluent. Simulation results and subsequent analysis show that the appropriate decrease in $\mathrm{L}_{\mathrm{S}}$ and reduction in $\mathrm{L}_{\mathrm{V}}$ between the two rows of fins can improve the convective heat transfer of the PCHE. A fully staggered arrangement of fins $\left(\mathrm{L}_{\mathrm{S}}=1.2\right)$ and an appropriate increase in the $\mathrm{L}_{\mathrm{V}}$ can mitigate pressure drop. The comprehensive performance of different channel geometries is compared by the performance evaluation criteria (PEC) in this study. It is shown that considering flow resistance and heat transfer, the comprehensive heat transfer performance can be enhanced by properly increasing the staggered distance and the vertical distance between fins. When $\mathrm{L}_{\mathrm{s}}=1.2 \mathrm{~mm}$ and $\mathrm{L}_{\mathrm{v}}=1.25 \mathrm{~mm}$, the PEC value of the staggered channel is the highest, which is $11.6 \%$ higher than that of the parallel channel on average.

Keywords: printed circuit heat exchanger; supercritical nitrogen; fins' configuration

\section{Introduction}

The printed circuit heat exchanger (PCHE) is highly valued with high heat transfer efficiency which can be used in harsh conditions, such as high temperature and pressure. The PCHE, as one of the most promising candidate heat exchangers in the terms of compact heat transfer, is composed of diffusion bonded plate arrays [1]. Narrow spaced microchannels are formed on these metal plates to serve as flow channels through chemical etching. In this paper, the supercritical fluid was used as the working fluid in the airfoil fin PCHE. Supercritical fluids are broadly applied in industrial fields including refrigeration engineering [2], power engineering [3], chemical engineering and aerospace engineering [4]. These fluids have special physical properties, having states between liquid and gas. They have attractive flow and transport characteristics, for example, diffusivity and viscosity close to gas and density nearly the same as liquids.

In recent years, different structures and cross-section shapes of channels in the PCHE have been widely researched. The heat transfer performances of PCHEs with straight channels were investigated experimentally by Wang et al. [5] and the effects of pressure and pseudo-critical points on heat transfer performance were studied. Zhao et al. [6] investigated the heat transfer and hydraulic characteristics of supercritical nitrogen in a straight PCHE. They studied the effect of inlet pressure and established a correlation between the Nusselt number and Fanning factor. Nikitin [7] investigated the heat transfer 
and flow resistance of a zigzag channel in the PCHE using supercritical $\mathrm{CO}_{2}$ experimental equipment. It was concluded by the author that the PCHE has very large maximal power density and compactness. Tsuzuki [8] published novel PCHEs with discontinuous Z-shaped fins for a three-dimensional channel structure. The results in this reference demonstrated that this new channel had better feature of flow and heat transfer compared with the previous consecutive Z-shaped channel. Ishizuka et al. [9] focused on the flow and heat transfer efficiencies of PCHEs under different variables, such as flow rates, pressures and temperatures. Lee et al. [10] reduced the pressure drop and improved the heat transfer characteristic of a zigzag channel by multi-objective optimization.

In addition to the traditional continuous structure of channels such as straight and Z-shaped channels, channels with discontinuous fins such as S-shaped and airfoil fins were proposed in the existing literature. This type of fin has superior thermal-hydraulic performance. The S-shaped channel was proposed by Ngo [11] and the comprehensive thermal-hydraulic performance of the PCHEs was compared with zigzag fins and S-shaped fins in [12]. The comparison indicated that the pressure factor of the S-shaped PCHE was at least four times less than that of the zigzag-shaped PCHE in a certain range of Reynolds number (Re).

Researchers have also studied the flow resistance and heat transfer performance of PCHEs with airfoil fins in [13-16]. Xu et al. [13] and Kim et al. [14] compared the performance of heat transfer capacity and pressure loss with different arrangements of fins in the PCHE. Chen et al. [15] and Kwon et al. [16] investigated the effect of different types of fins on the overall performance of the PCHE. Tsuzuki [9] showed that the uniform flow velocity profile and elimination of countercurrent and eddy current can reduce the pressure drop. Later, Kim [17] showed that the airfoil fins could inhibit the separation of flow, which could be better for the mitigation of pressure drop compared with S-shaped fins. Ma et al. [18] studied the effect of fin-end wall manufactured by the chemical etching process in an airfoil fin PCHE. They concluded that the heat transfer performance was enhanced by a non-ideal profile with a longitudinal spacing of $1.63 \mathrm{~mm}$. Only when the longitudinal spacing was less than $1.88 \mathrm{~mm}$ could the heat transfer enhancement be more obvious.

Numerous investigations on PCHE flow and heat transfer performance at high temperature and pressure were carried out at present. However, the research on PCHE performance at cryogenic temperatures is still scarce [19]. Therefore, it is very imperative to study PCHE performance at cryogenic temperatures, especially in the field of LNG regasification $[20,21]$. To study the gasification performance of LNG in a PCHE, a common approach in the experiment is to research the gasification performance of liquid nitrogen due to the flammability and explosibility of NG produced during the regasification of LNG [22,23].

It can be seen based on the literature review carried out in the previous paragraphs that the PCHE can have straight, Z-shaped, S-shaped and airfoil fin channels. Considering the pressure drop and heat transfer, the airfoil fin PCHE has better comprehensive performance. However, the effects of the detailed arrangement of fins in the PCHE using supercritical nitrogen as a working fluid in extremely low temperatures and extremely high pressure have not been thoroughly investigated [24]. Compared to existing work, the study carried out in this paper has the following novel contributions:

1. The heat transfer and flow resistance of supercritical nitrogen in the PCHE with different arrangements of airfoil fins are investigated numerically.

2. The local characteristics along the flow direction in the PCHE according to different arrangements of airfoil fins are analyzed.

3. The overall pressure drops and heat transfer performance of the PCHE with respect to varying vertical and staggered distances of fins are investigated and the performance evaluation criteria (PEC) are compared to find the best arrangement of fins in this study. 


\section{Numerical Methodology}

\subsection{Physical Model and Boundary Condition}

The entire airfoil flow channel PCHE is composed of tens of thousands of periodically repeating tiny flow channels. It requires a high calculation cost to simulate the internal flow and heat transfer characteristics of all flow channels in the whole core. In this section, the flow and heat transfer of the airfoil fins channel are mainly studied. When the boundary conditions of the airfoil fins channel are the same, the flow and heat transfer characteristics are the same in the direction perpendicular to the flow. Therefore, for the convenience of simulation and research, the 3-D model for numerical calculations is simplified as a flow channel with two rows of airfoil fins in the red frame in Figure 1. The structure of the flow channel shown in Figure 1 is periodic in both transverse and longitudinal direction.

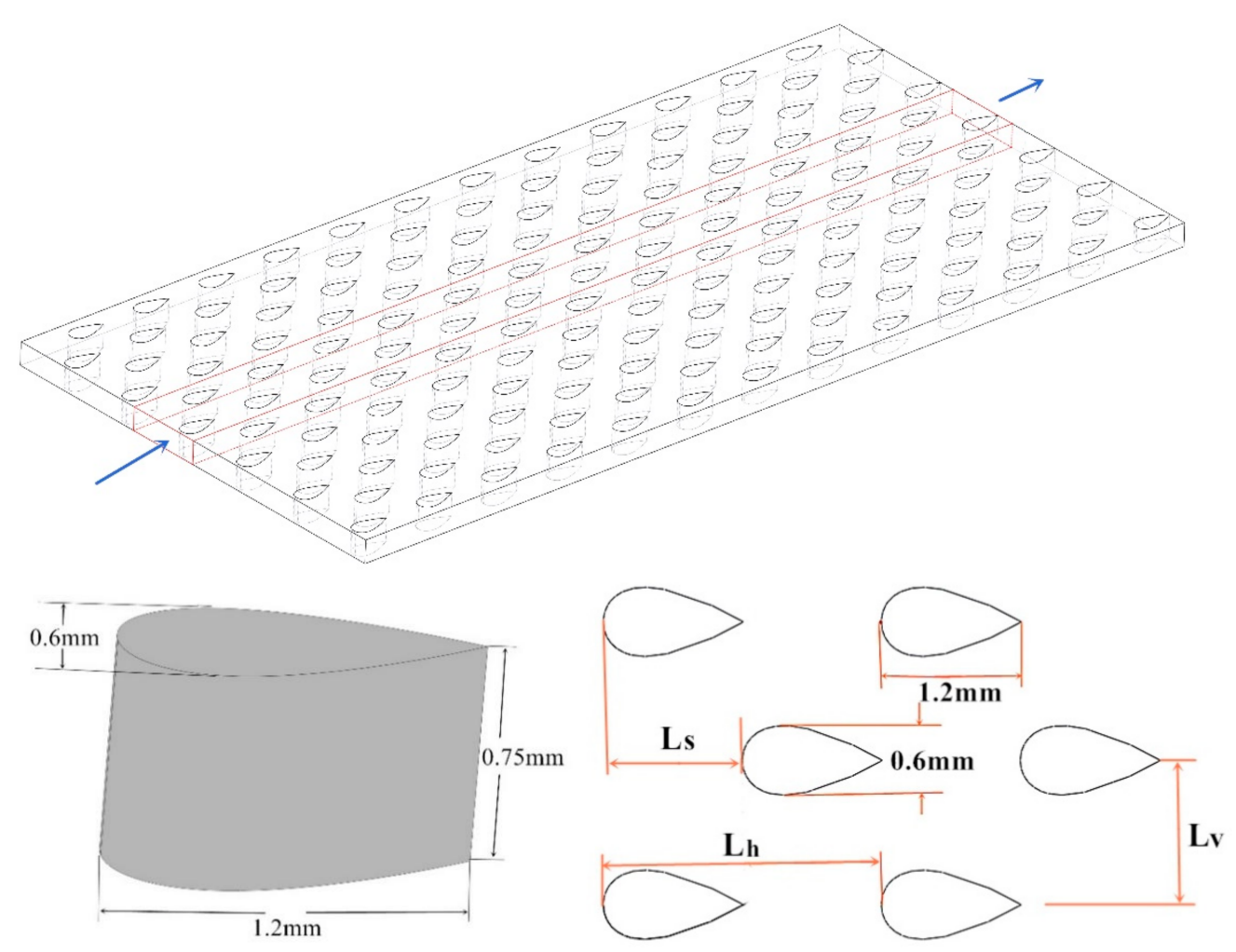

Figure 1. Schematic diagram of internal core structure of airfoil fin PCHE.

The NACA0050-4.5/2.6 airfoil (the airfoil relative maximum thickness as a percentage of the chord is $50 \%$, the leading-edge radius index is 4.5 and the chordwise-position of airfoil maximum thickness is $26 \%$ ) is used as the shape of the fin. The symmetrical airfoil fins are defined by the fin height $(\mathrm{H})$, fin width $(\mathrm{W})$ and fin length $(\mathrm{L})$, which are set to $0.75 \mathrm{~mm}, 0.6 \mathrm{~mm}$ and $1.2 \mathrm{~mm}$, respectively, as shown in Figure 1 . The different fin structures and arrangements of the channel do not increase the processing cost. Figure 1 further shows the flow channel with airfoil fins and different distances between the airfoil fins $\left(L_{s}\right.$, $\mathrm{L}_{\mathrm{V}}, \mathrm{L}_{\mathrm{h}}$ ). The $\mathrm{L}_{\mathrm{s}}$ presents staggered pitch, $\mathrm{L}_{\mathrm{v}}$ indicates the vertical pitch of the adjacent rows and $\mathrm{L}_{\mathrm{h}}$ indicates the horizontal pitch of the adjacent fins. The height of the flow channel in the model is $0.75 \mathrm{~mm}$ and the length is $400 \mathrm{~mm}$, which is consistent with the height and length of the experimental heat exchanger. Figure 2 shows the boundary conditions of the 3 -D model. The inlet temperature was $103 \mathrm{~K}$, the mass flow rate at the inlet ranged from $0.0003461 \mathrm{~kg} / \mathrm{s}$ to $0.0004384 \mathrm{~kg} / \mathrm{s}$, and the inlet pressure was set at $6 \mathrm{MPa}$. The outlet was the pressure outlet, the left and right sides were periodic, and the upper and lower sides were set as constant heat flux. 


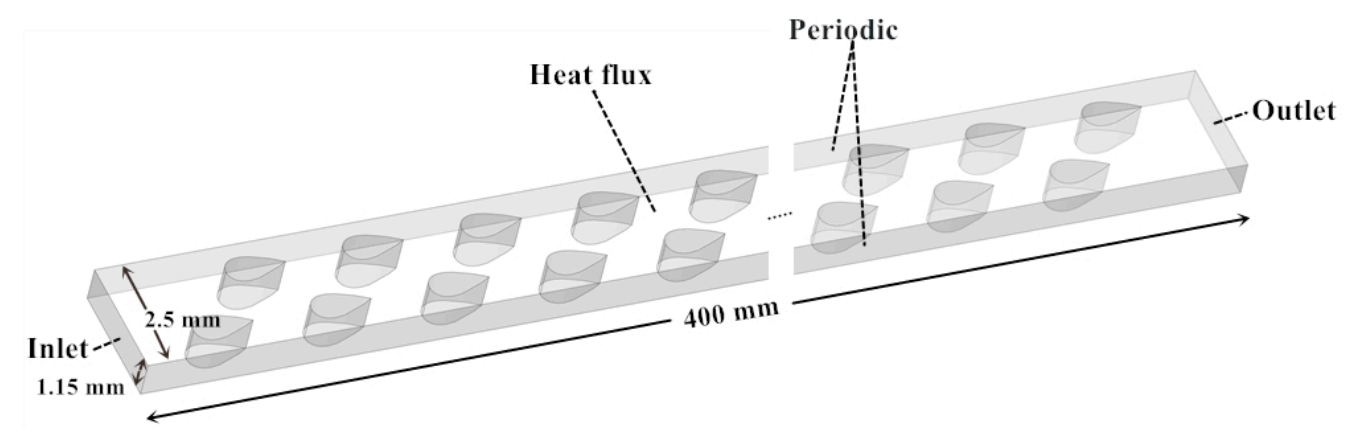

Figure 2. Schematic diagram of the computational model.

\subsection{Numerical Model and Grid Independence}

The numerical solutions for the PCHE with different fin arrangements were obtained using ANSYS Fluent [25]. The tested shear stress transport (SST) $\kappa-\omega$ model [26-29] showed that the model was suitable for turbulent flow and heat transfer at supercritical pressure. Therefore, in this paper, the SST $\kappa-\omega$ model with enhanced wall treatment and the QUICK scheme were employed for numerical simulations and the momentum equation, respectively. Other equations were discretized using a second-order upwind scheme. In addition, the semi-implicit method pressure linked equation (SIMPLE) was used to couple the velocity with pressure. The governing equations for the simulation have been described in detail in our previous work [24].

The mesh was optimized to ensure that the non-dimensional length $(y+)$ at the first node close to the wall was less than 0.5 , so as to calculate the viscous sub-layer accurately. In order to ensure the accuracy of calculation, a boundary layer was applied to the wall of the flow passage to carry out mesh encryption. The boundary layer was equipped with eight columns of meshes. The thickness of the first mesh and increasing factor were $0.01 \mathrm{~mm}$ and 1.1, respectively. Figure 3 shows the zoomed-in image of the mesh and boundary layer.

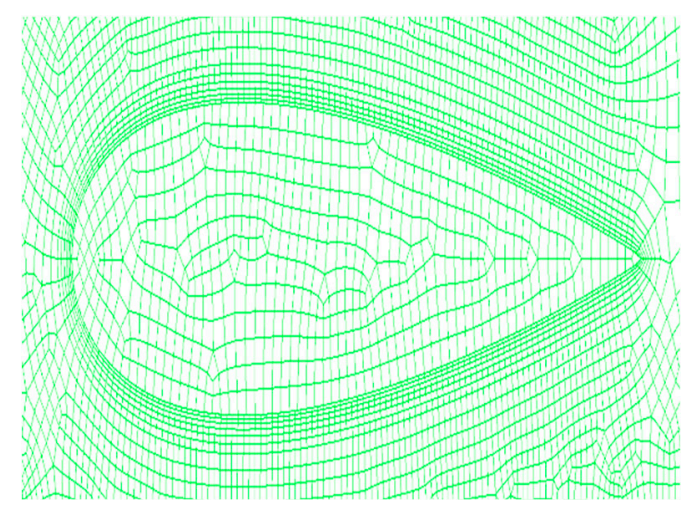

Figure 3. The zoomed-in image of the mesh and boundary layer.

To ensure the accuracy of numerical results and save computational resources, grid independence needs to be verified. Five sets of grid numbers: 3,523,635, 4,804,956, 5,724,613, $6,406,608$ and $7,687,930$, were compared to analyze the influence of mesh density on simulation results in Table 1. Considering the accuracy of outlet temperature and grid quantity, the mesh number is selected as 6,406,608.

Table 1. Cases of mesh independence study.

\begin{tabular}{ccccccc}
\hline Case & $\mathbf{3 , 5 2 3 , 6 3 5}$ & $\mathbf{4 , 8 0 4 , 9 5 6}$ & $\mathbf{5 , 7 2 4 , 6 1 3}$ & $\mathbf{6 , 4 0 6 , 6 0 8}$ & $\mathbf{7 , 6 8 7 , 9 3 0}$ & $\begin{array}{c}\text { Experimental } \\
\text { Data }\end{array}$ \\
\hline $\begin{array}{c}\text { Outlet } \\
\text { temperature }\end{array}$ & 281.56 & 282.92 & 283.61 & 284.18 & 284.06 & 284.5 \\
\hline
\end{tabular}




\subsection{Thermal Physical Properties of Supercritical Nitrogen}

The thermal physical properties of supercritical nitrogen are special. The physical properties of supercritical nitrogen vary significantly around the pseudo-critical point, which changes with the increase in pressure. Physical properties (thermal conductivity, specific heat, density and viscosity) of nitrogen at $6 \mathrm{MPa}$ could be obtained according to the Standard Reference Database (REFPROP) [30]. Figure 4 shows that the thermal conductivity and dynamic viscosity decrease sharply and then increase slightly with increasing temperature. The specific heat capacity reaches a peak value near the pseudo-critical point, then decreases sharply and reaches a nearly constant value. It can be concluded that the thermal physical properties of nitrogen depend significantly on temperature, which varies greatly in the heat exchanger. The temperature difference between the inlet and outlet of the PCHE is relatively large, which leads to the thermal physical properties of supercritical nitrogen changing very sharply with the temperature. Therefore, we fitted the main physical property parameters as a function of temperature into a polynomial, and used the PIECEWISE-POLYNOMIAL function in FLUENT to input the fitting polynomial into the physical property of the software material according to the temperature interval. Table 2 shows the piecewise-polynomial function of physical properties of nitrogen at $6 \mathrm{MPa}$.

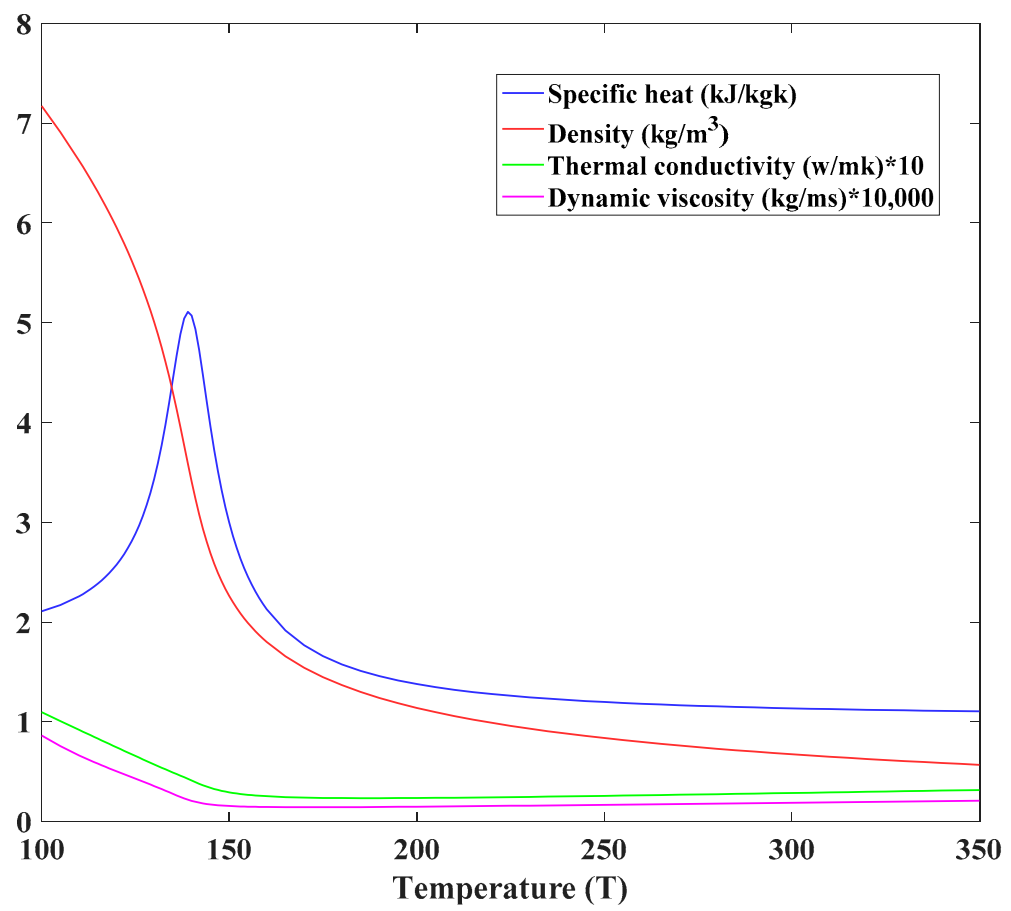

Figure 4. Thermal-physical properties of supercritical nitrogen. 
Table 2. Piecewise-polynomial function of physical properties of nitrogen at $6 \mathrm{Mpa}$.

\begin{tabular}{cl}
\hline Temperature Range (K) & Density \\
\hline $100-140$ & $\rho=6586.80192-154.44382 \mathrm{~T}+1.390229 \mathrm{~T}^{2}-4.33 \times 10^{-3} \mathrm{~T}^{3}$ \\
$140-200$ & $\rho=61544.16687-1366.704 \mathrm{~T}+11.43075 \mathrm{~T}^{2}-0.04253 \mathrm{~T}^{3}+0.0000593151 \mathrm{~T}^{4}$ \\
$200-350$ & $\rho=476.54019-3.09919 \mathrm{~T}+0.00784 \mathrm{~T}^{2}-0.00000688434 \mathrm{~T}^{3}$ \\
\hline & Specific Heat \\
$100-140$ & $\mathrm{C}_{\mathrm{p}}=-34972.79899+1134.1696 \mathrm{~T}-11.57553 \mathrm{~T}^{2}+3.944 \times 10^{-2} \mathrm{~T}^{3}$ \\
$140-200$ & $\mathrm{C}_{\mathrm{p}}=269355.00689-4401.41191 \mathrm{~T}+24.12557 \mathrm{~T}^{2}-0.0441 \mathrm{~T}^{3}$ \\
$200-350$ & $\mathrm{C}_{\mathrm{p}}=2961.5785-13.56096 \mathrm{~T}+0.03285 \mathrm{~T}^{2}-0.0000265589 \mathrm{~T}^{3}$ \\
& Thermal Conductivity \\
$100-140$ & $\lambda=0.23565-2.39661 \times 10^{-4} \mathrm{~T}-1.51519 \times 10^{-5} \mathrm{~T}^{2}+4.96296 \times 10^{-8} \mathrm{~T}^{3}$ \\
$140-200$ & $\lambda=1.60019-0.02618 \mathrm{~T}+1.44562 \times 10^{-4} \mathrm{~T}^{2}-2.65559 \times 10^{-7} \mathrm{~T}^{3}$ \\
$200-350$ & $\lambda=0.03415-1.69217 \times 10^{-4} \mathrm{~T}+7.47591 \times 10^{-7} \mathrm{~T}^{2}-8.10651 \times 10^{-10} \mathrm{~T}^{3}$ \\
\hline $100-140$ & Viscosity \\
$140-200$ & $\mu=9.20938 \times 10^{-4}-1.78064 \times 10^{-5} \mathrm{~T}+1.27952 \times 10^{-7} \mathrm{~T}^{2}-3.33535 \times 10^{-10} \mathrm{~T}^{3}$ \\
$200-350$ & $\mu=4.109 \times 10^{-3}-9.27404 \times 10^{-5} \mathrm{~T}+7.86199 \times 10^{-7} \mathrm{~T}^{2}-2.08564 \times 10^{-9} \mathrm{~T}^{3}$ \\
& $\mu=1.32819 \times 10^{-5}-2.71427 \times 10^{-8} \mathrm{~T}+2.3346 \times 10^{-10} \mathrm{~T}^{2}-2.66866 \times 10^{-13} \mathrm{~T}^{3}$ \\
\hline
\end{tabular}

\subsection{Model Validation}

The thermal hydraulic performance of supercritical nitrogen was investigated numerically in this study. Experimental data and numerical data were compared to verify the accuracy of the numerical model. Figure 5 shows photographs of the experimental PCHE and system. The airfoil fin PCHE in the experiment was manufactured by $316 \mathrm{~L}$ grade stainless steel. The chord length of the airfoil fin was $1.2 \mathrm{~mm}$ and the maximum thickness was $0.6 \mathrm{~mm}$. The inlet temperature of nitrogen was $103 \mathrm{~K}$ where the mass flux ranged from $0.0003461 \mathrm{~kg} / \mathrm{s}$ to $0.0004384 \mathrm{~kg} / \mathrm{s}$ at $6 \mathrm{Mpa}$, corresponding to the numerical operating conditions [24]. The differences between the experimental and the numerical data in temperature and pressure drop were defined as the following form:

$$
\text { Error }=\left|\frac{\text { Numerication }- \text { Experiment }}{\text { Experiment }} \times 100 \%\right|
$$

The differences of outlet temperature and pressure drop between experimental results and numerical data for different mass flux are shown in Table 3 . The uncertainty for the outlet temperature was within $0.84 \%$ and the maximum error of pressure drop was $4.51 \%$ under the operating pressure of $6 \mathrm{Mpa}$. As these errors are small, we can conclude that the numerical results were consistent with experimental results, and the numerical models and methods were reasonably accurate.

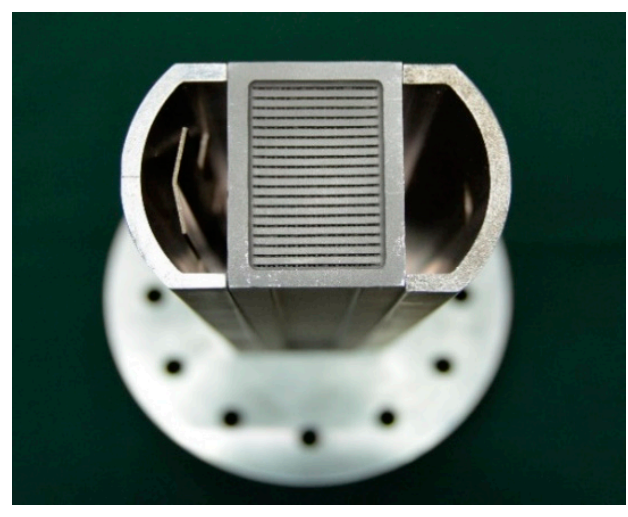

(a)

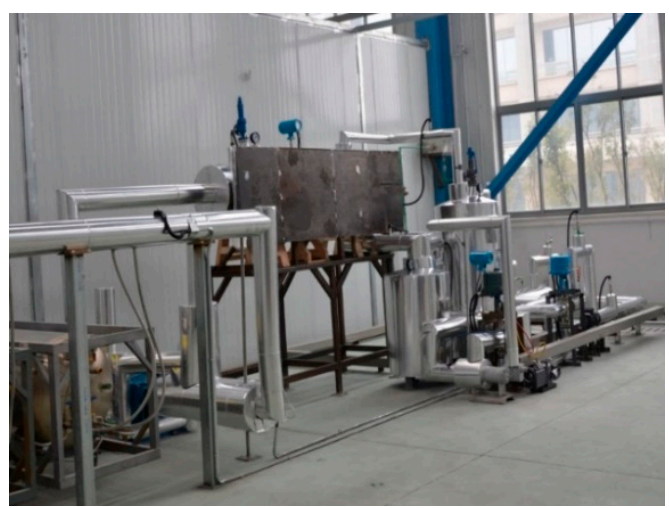

(b)

Figure 5. Diagrams of (a) experimental PCHE; (b) system. 
Table 3. Comparison between numerical and experimental data.

\begin{tabular}{ccc}
\hline \multirow{2}{*}{ Mass Flux $\left(\mathbf{k g} / \mathbf{m}^{\mathbf{2}} \mathbf{s}\right)$} & \multicolumn{2}{c}{ Error $\mathbf{( \% )}$} \\
\cline { 2 - 3 } & Temperature & Pressure Drop \\
\hline 184.6 & 0.62 & 2.32 \\
190.7 & 0.51 & 2.01 \\
196.9 & 0.34 & 2.25 \\
203.1 & 0.16 & 0.66 \\
209.2 & 0.18 & 1.40 \\
215.4 & 0.22 & 2.82 \\
221.5 & 0.23 & 3.19 \\
227.7 & 0.78 & 1.28 \\
233.8 & 0.84 & 4.51 \\
\hline
\end{tabular}

\subsection{Calculation Methodology}

As the characteristic length of the flow channel, the hydraulic diameter $D_{h}$, defined as four times the cross-sectional area divided by the perimeter of the circular and non-circular tubes, is of great significance for dimensional analysis. The arrangement of the airfoil fins shown in Figure 1 is periodic, and the hydraulic diameter can be calculated as follows [24]:

$$
\begin{gathered}
\mathrm{V}=\left(\mathrm{LW}-S_{a}\right) \mathrm{t} \\
\mathrm{S}=2\left(P_{a} t / 2\right)+2\left(\mathrm{~L}-L_{a}\right) \mathrm{t}+2\left(\mathrm{WL}-S_{a}\right), \\
D_{h}=4 V / S,
\end{gathered}
$$

where $S_{a}$ and $P_{a}$ indicate the area at the top and the perimeter of the airfoil fin, respectively, as shown in Figure 6, and $S$ and $V$ are the side surface area and volume of the airfoil fin, respectively, while $L_{a}$ indicates the length of the airfoil fin, as shown in Figure 6.

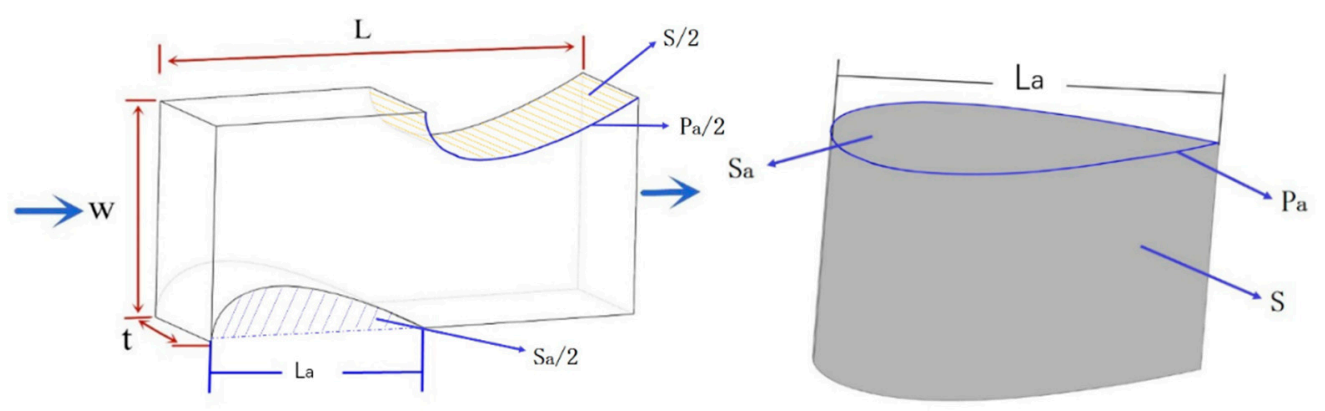

Figure 6. Schematic diagram for calculation of hydraulic diameter.

The average convective heat transfer coefficient was selected to evaluate the heat transfer performance of the PCHE with airfoil fins. The average convective heat transfer coefficient, $\mathrm{h}$, is calculated from the solver data as:

$$
\mathrm{h}=q_{w} /\left(T_{\text {wall }}-T_{b}\right),
$$

where $q_{w}$ indicates the area-average wall heat flux, and $T_{w a l l}$ is the area-average wall temperature. The bulk mean temperature of nitrogen is represented by $T_{b}$, which is calculated as [31]:

$$
T_{b}=\frac{\sum_{j=1}^{n} T_{j} \rho_{j}\left|\overrightarrow{v_{j}} \cdot \overrightarrow{A_{j}}\right|}{\sum_{j=1}^{n} \rho_{j}\left|\overrightarrow{v_{j}} \cdot \overrightarrow{A_{j}}\right|},
$$


where $T_{j}, \rho_{j}$, and $\underset{v_{j}}{\rightarrow}$ are the nitrogen temperature, density and velocity vector in the $j$ th cell, respectively, and $\vec{A}_{j}$ is the flow area vector of the jth cell. The physical properties of nitrogen are dependent on the bulk mean temperature.

The intensity of convective heat transfer can also be characterized by the Nusselt number, which is expressed in the following form:

$$
\mathrm{Nu}=\mathrm{h} D_{h} / \lambda,
$$

where $\lambda$ is the thermal conductivity of nitrogen.

The pressure drop, $\Delta \mathrm{P}$, of the channel in the heat exchanger is determined by acceleration and friction losses. It is given as follows:

$$
\Delta \mathrm{P}=\Delta P_{\text {acceleration }}+\Delta P_{\text {friction }}
$$

and can be measured at the inlet and outlet of the airfoil PCHE through the pressure sensor. The friction pressure drop can be calculated from the $\Delta \mathrm{P}$ and the acceleration pressure drop. The pressure drop due to acceleration pressure drop is calculated as:

$$
\Delta \mathrm{P}_{\text {acceleration }}=\rho_{\text {out }} v_{\text {out }}^{2}-\rho_{\text {in }} v_{\text {in }}^{2}
$$

The frictional pressure drop is given as:

$$
\Delta P_{\text {friction }}=2 f \frac{L}{D_{h}} \rho_{b} v_{b}^{2},
$$

where $f$ is the Fanning friction factor, which can be calculated using the above equations as:

$$
f=\frac{\left(\Delta \mathrm{P}-\Delta P_{\text {acceleration }}\right) D_{h}}{2 \rho_{b}^{2} v_{b} L} .
$$

The Performance Evaluation Criteria (PEC) [32] are computed using Equation (12):

$$
\mathrm{PEC}=\frac{N u / N u_{0}}{\left(f / f_{0}\right)^{1 / 3}} .
$$

where the subscript " 0 " corresponds to the parallel arrangement of the channel.

\section{Results and Discussion}

The effects of different staggered distance $\left(\mathrm{L}_{\mathrm{s}}\right)$ and transverse distance $\left(\mathrm{L}_{\mathrm{v}}\right)$ of airfoil fin arrangements on the thermal hydraulic performance of supercritical nitrogen in the PCHE are numerically simulated using ANSYS Fluent in the present study. The fin arrangements mainly affect the thermal hydraulic performance of the PCHE by increasing the heat transfer area and interfering with the flow. In fact, the height of the channel is very small, which results in the fin having a small side area. The lateral area of the fin counteracts the heat transfer area occupied by the fin on the inner surface of the channel. As a result, the enlargement of the heat transfer area is very limited. Therefore, the fin arrangement plays a significant part in improving the performance of the airfoil PCHE. In this study, the staggered distance $\left(L_{s}\right)$ of the airfoil fins was varied as $0 \mathrm{~mm}, 1 \mathrm{~mm}$ and $1.2 \mathrm{~mm}$ and the transverse distance $\left(\mathrm{L}_{\mathrm{v}}\right)$ was varied as $1 \mathrm{~mm}$ and $1.25 \mathrm{~mm}$.

\subsection{Local Characteristics of Different Fin Arrangements}

Figure 7a shows the velocity vector of supercritical nitrogen in the channel near the outlet arranged in parallel and staggered fins with a mass flux of $227.7 \mathrm{~kg} /\left(\mathrm{m}^{2} \mathrm{~s}\right)$. As can be seen from the velocity vector distribution of the top three flow channels, when $L_{v}$ is fixed at $1.25 \mathrm{~mm}$, it is observed that the velocity distribution becomes more stable as the $\mathrm{L}_{\mathrm{s}}$ increases from $0 \mathrm{~mm}$ to $1.2 \mathrm{~mm}$. The distribution of red and blue velocity vectors is 
significantly different in parallel arrangement, and the velocities suddenly increase and then decrease between the two adjacent fin heads. The maximum velocity of the parallel flow channel at the minimum section is larger than that of the staggered flow channel, which can be seen from the degree and number of red vector arrows. When the fins were completely staggered $\left(L_{s}=1.2 \mathrm{~mm}\right)$, the vertical distance of $1 \mathrm{~mm}$ and $1.25 \mathrm{~mm}$ between the adjacent rows of fins had no obvious difference in the velocity distribution, and $\mathrm{L}_{\mathrm{s}}$ further decreased to $0.8 \mathrm{~mm}$, indicating a higher velocity and a more uniform distribution. Since the fin structure is wide head and narrow tail, it is easier to form a streamline when the fins are staggered. As the tail of the fin is narrow, there is nearly no vortex at the tail of the fin.

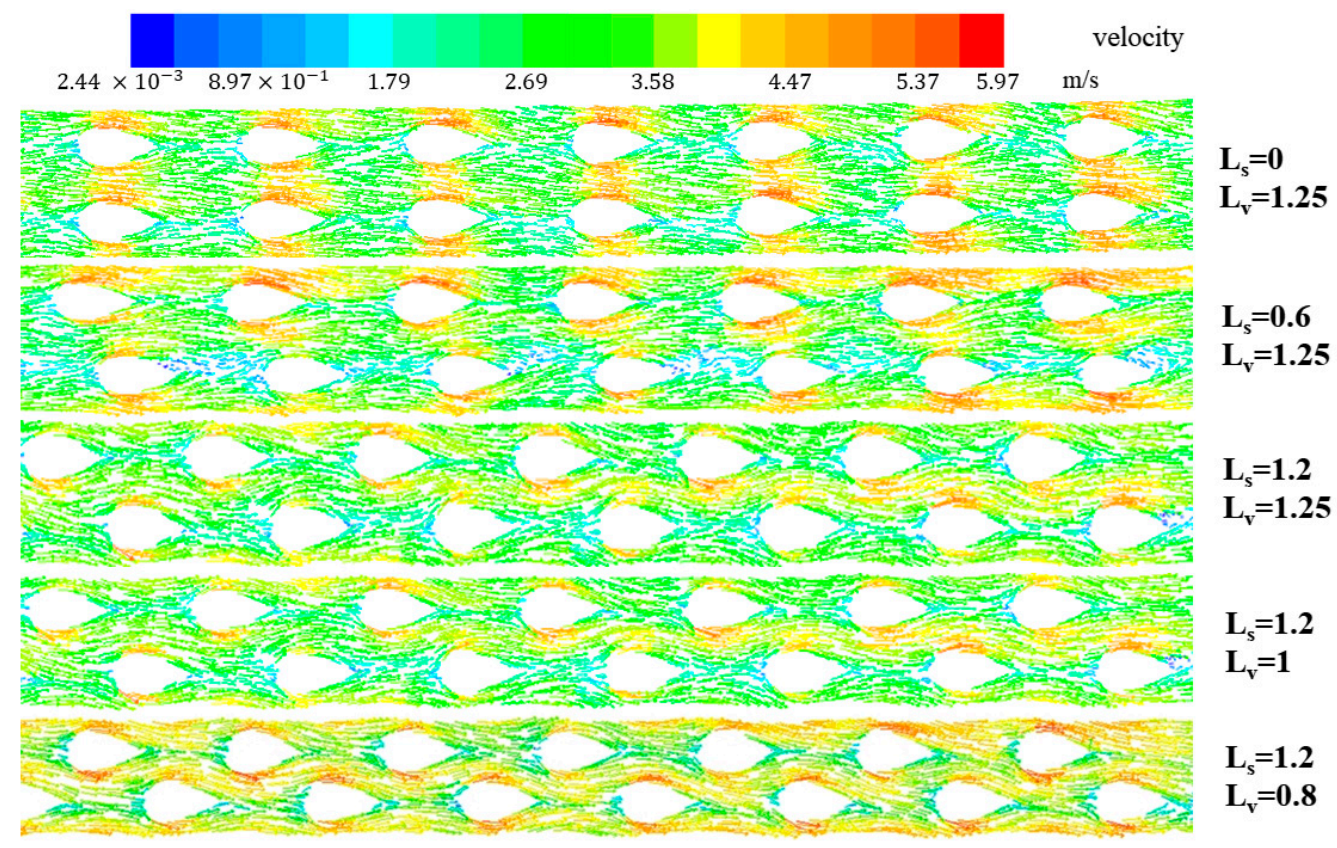

(a)

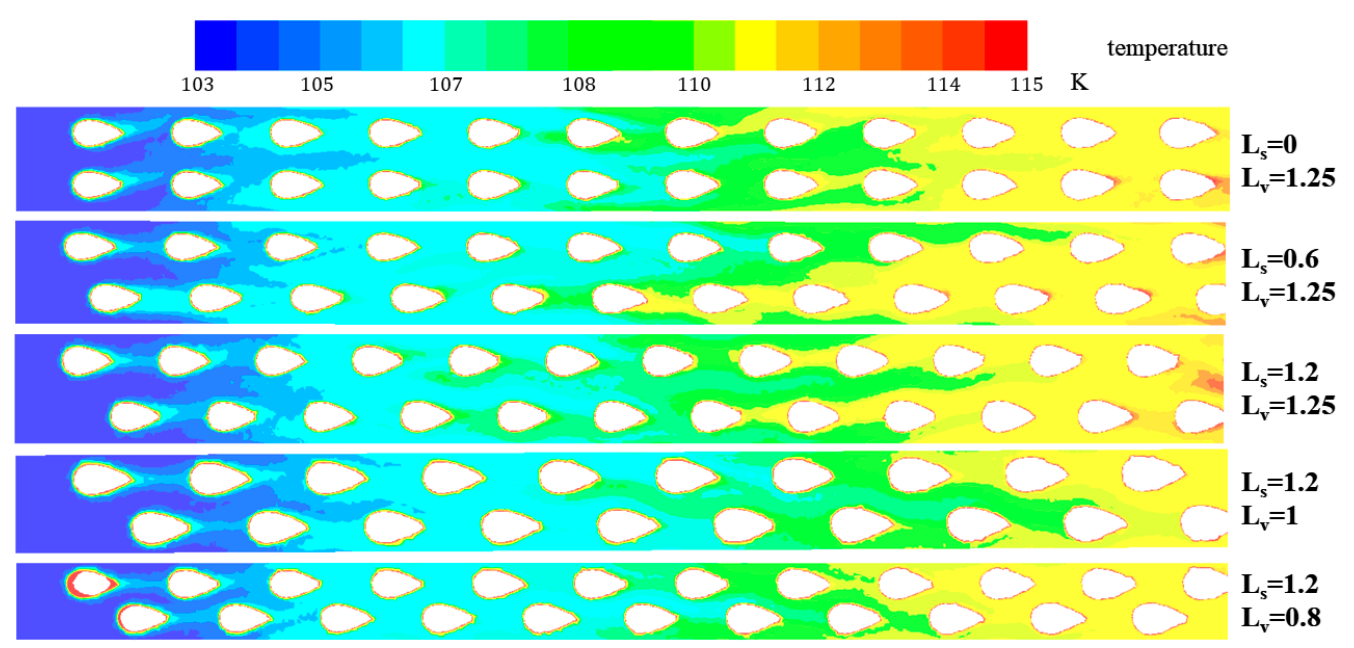

(b)

Figure 7. Velocity vector and temperature distribution: (a) velocity vector distribution near the outlet; (b) temperature distribution near the inlet.

Figure $7 \mathrm{~b}$ shows the temperature distribution near the inlet with varying $\mathrm{L}_{\mathrm{S}}$ and $\mathrm{L}_{\mathrm{V}}$, where the inlet temperature and pressure are $103 \mathrm{~K}$ and $6 \mathrm{MPa}$, respectively. The 
temperature of all the flow channels increases by $10 \mathrm{~K}$ at $\mathrm{x}=28 \mathrm{~mm}$. The temperature near the fin tail is higher than that in the main flow area, especially in the case of a complete staggered arrangement of $\mathrm{L}_{\mathrm{s}}=1.2 \mathrm{~mm}$ and $\mathrm{L}_{\mathrm{v}}=1.25 \mathrm{~mm}$. The reason for this high temperature is the velocity of the fin tail region being lower than that of the middle region of the flow channel. The sudden increase and decrease in velocity in the cross section of the parallel channel is beneficial for distributing the temperature uniformly in the fin tail. At the inlet section, the effect of the $\mathrm{L}_{\mathrm{S}}=1.2 / \mathrm{L}_{\mathrm{v}}=0.8$ arrangement on supercritical nitrogen is relatively severe, resulting in a relatively strong local heat transfer capacity in this region, so there is a local rise in temperature around the fin.

The local average velocity of the cross section along the channel is shown in Figure 8a. It can be observed that the increasing trend of the velocity along the channel is in the consistent trend and becomes steeper under different fin arrangements. This is due to the rapid decrease in the density and viscosity of supercritical nitrogen in the flow channel. However, within the distance from $315 \mathrm{~mm}$ to $340 \mathrm{~mm}$ from the entrance, the increase in velocity disappears and becomes a decrease in velocity instead. This trend is because the density and dynamic viscosity of supercritical nitrogen change from a sharp decrease to a gradual increase in viscosity and a gentle decrease in density, leading to a decrease in velocity.

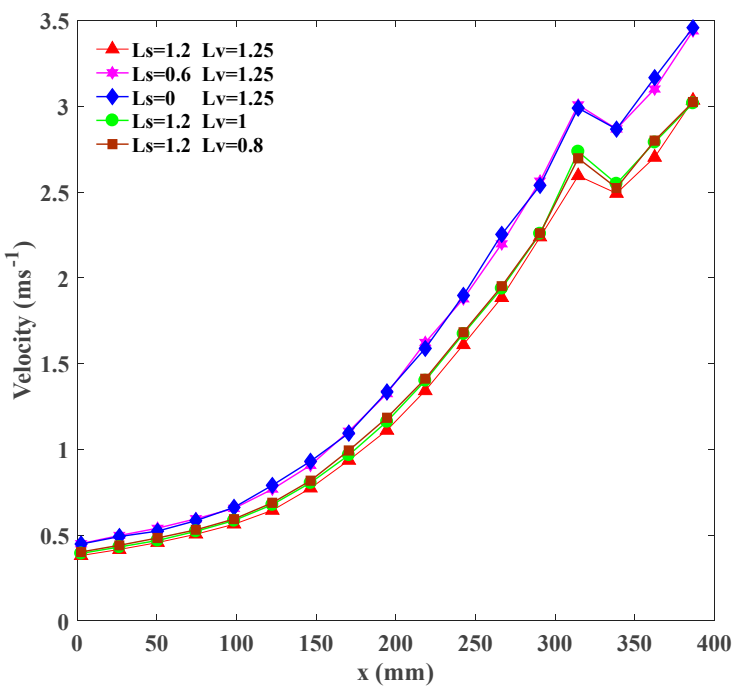

(a)

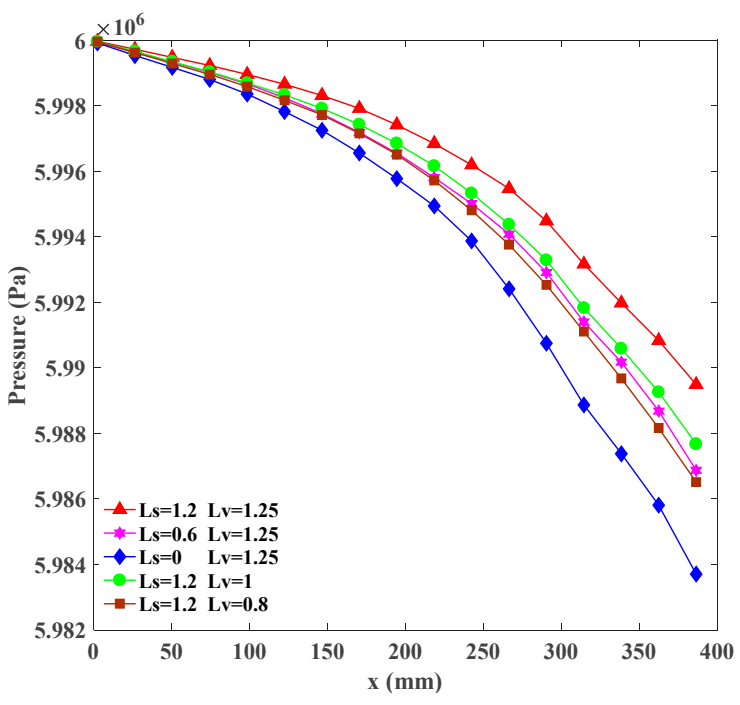

(b)

Figure 8. The average velocity and average pressure of the local cross section along the channel: (a) average velocity; (b) average pressure.

Figure $8 \mathrm{~b}$ shows the pressure distribution of the flow channel with different fin arrangements along the channel. The pressure in the flow channel decreases gradually along the flow direction, and the decreasing extent is more and more large, owing to a rapid increase in velocity during the heat transfer process. In addition, when the $\mathrm{L}_{\mathrm{s}}$ increases from 0 to $1.2 \mathrm{~mm}$, the change in pressure becomes lower under the condition of constant $\mathrm{L}_{\mathrm{v}}$. At the same staggered distance $\left(\mathrm{L}_{\mathrm{s}}=1.2 \mathrm{~mm}\right)$, reducing the vertical distance between two rows of fins can lead to an increased pressure reduction. This increase is caused by a decrease in fin vertical distance that increases the flow velocity.

\subsection{Overall Performance of Different Fin Arrangements}

Figure 9a compares the average convective heat transfer coefficients of the PCHE for different fin arrangements at different mass flux values. The figure indicates that the average convective heat transfer coefficient increases with increasing mass flux. With a reduction in the staggered distance, the convective heat transfer performance becomes stronger. When the $\mathrm{L}_{\mathrm{v}}$ remains constant, the convective heat transfer performance is enhanced by decreasing the value of $L_{S}$. In the case of parallel arrangement, a sudden 
increase and decrease in velocity will generate strong disturbance, which can enhance convective heat transfer. In addition, when $L_{s}$ is at a constant value of $1.2 \mathrm{~mm}$, the vertical distance of $\mathrm{L}_{\mathrm{v}}=0.8 \mathrm{~mm}$ has a stronger convective heat transfer performance than that $\mathrm{L}_{\mathrm{v}}=1 \mathrm{~mm}$ and $\mathrm{L}_{\mathrm{v}}=1.25 \mathrm{~mm}$. Figure $9 \mathrm{~b}$ depicts the overall Nusselt number $(\mathrm{Nu})$ versus Re. The Nu also increases as the Re increases; however, when Re is greater than $1.4 \times 10^{5}$, the increase degree of $\mathrm{Nu}$ decreases. Therefore, appropriate reductions in the staggered distance $\left(\mathrm{L}_{\mathrm{S}}\right)$ and vertical distance between the two rows of fins $\left(\mathrm{L}_{\mathrm{V}}\right)$ can improve the convective heat transfer of the PCHE.

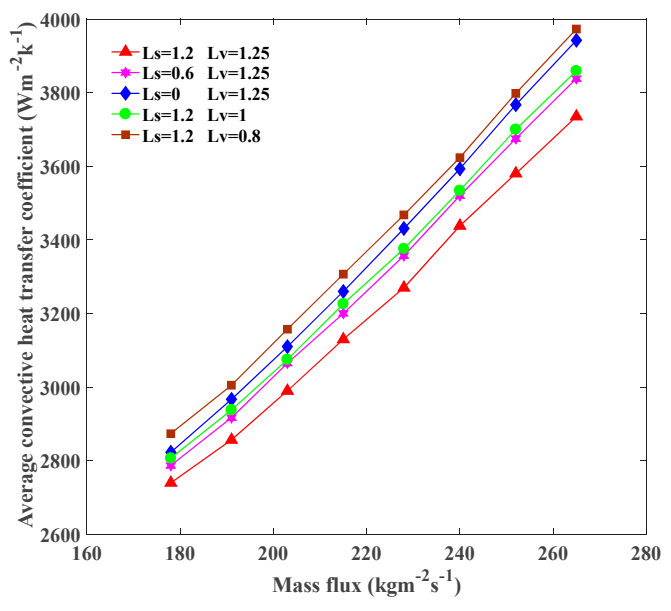

(a)

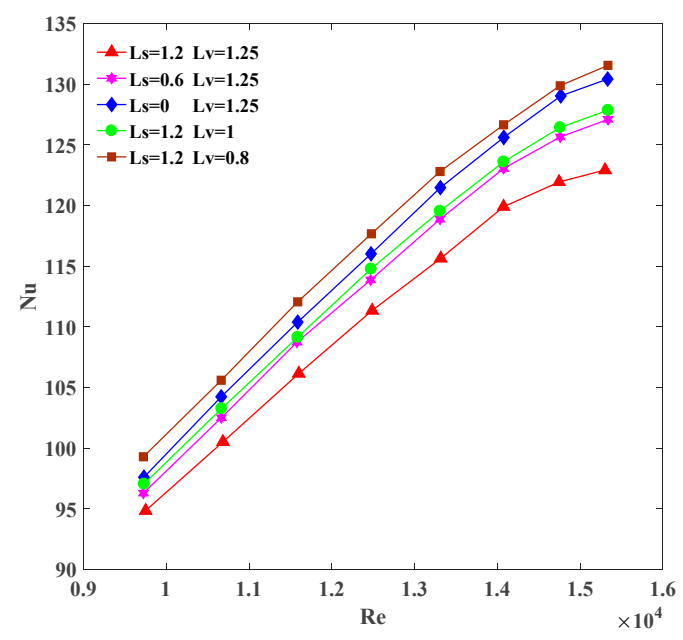

(b)

Figure 9. The average convective heat transfer coefficient versus mass flux and Nu versus Re for different fin arrangements: (a) average convective heat transfer coefficient versus mass flux; (b) Nu versus Re.

In addition, in order to summarize the heat transfer characteristics of supercritical nitrogen in the airfoil PCHE, a new correlation formula of average convective heat transfer is proposed. By fitting the average convective heat transfer coefficient of the simulation results, the new correlation formula for $h$ is obtained:

$$
h=0.1238 C_{p} \rho \nu D_{h}^{-0.2798} \mu^{-0.8662} \lambda^{1.146}
$$

where $C_{p}, \rho, v$, and $\mu$ are the specific heat capacity, density, flow rate and viscosity of nitrogen, respectively.

The pressure drop of the PCHE for different fin arrangements under varying values of mass flux is shown in Figure 10a. The pressure drop slope decreases with the increase in mass flux. At the same vertical distance $\left(\mathrm{L}_{\mathrm{v}}=1.25 \mathrm{~mm}\right)$, the pressure drop decreases with the increase in $\mathrm{L}_{\mathrm{s}}$. Therefore, when $\mathrm{L}_{\mathrm{s}}=1.2 \mathrm{~mm}$, the average pressure drop corresponding to each mass flow is the minimum of $9.0 \times 10^{3} \mathrm{~Pa}$, only $56.6 \%$ of the parallel arrangement. The pressure loss of the completely staggered arrangement $\left(\mathrm{L}_{\mathrm{s}}=1.2 \mathrm{~mm}\right)$ reduces by $35.5 \%$ on average compared with that of the parallel arrangement. In addition, for the same $\mathrm{L}_{\mathrm{s}}$ of $1.2 \mathrm{~mm}$, the pressure loss decreases by $34.9 \%$ on average as the vertical distance increases from $0.8 \mathrm{~mm}$ to $1.25 \mathrm{~mm}$.

Figure 10b shows the Fanning friction factor versus the variation of Re in the flow channel with different $\mathrm{L}_{\mathrm{v}}$ and $\mathrm{L}_{\mathrm{S}}$. With the increase in Re, the Fanning friction factor decreases. The Fanning friction factor of the completely staggered arrangement $\left(\mathrm{L}_{\mathrm{s}}=1.2 \mathrm{~mm}\right)$ reduces by $37 \%$ on average compared with that of the parallel arrangement, and the Fanning friction factor for a vertical distance of $\mathrm{L}_{\mathrm{V}}=0.8 \mathrm{~mm}$ increases by $35 \%$ on average compared with that for $\mathrm{L}_{\mathrm{v}}=1.25 \mathrm{~mm}$. These effects are a result of the velocity of the staggered channel being more uniform than that of the parallel flow channel and the wide head and narrow tail being more likely to form a streamlined structure, which eliminates the reverse flows 
and eddies. Therefore, appropriate increases in the staggered distance $\left(L_{s}\right)$ and vertical distance between the two rows of fins $\left(\mathrm{L}_{\mathrm{V}}\right)$ are more suitable for reducing pressure loss.

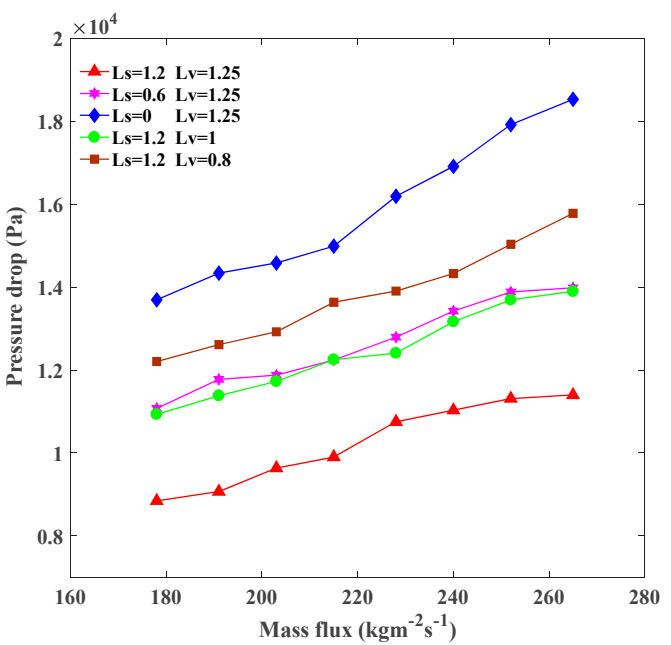

(a)

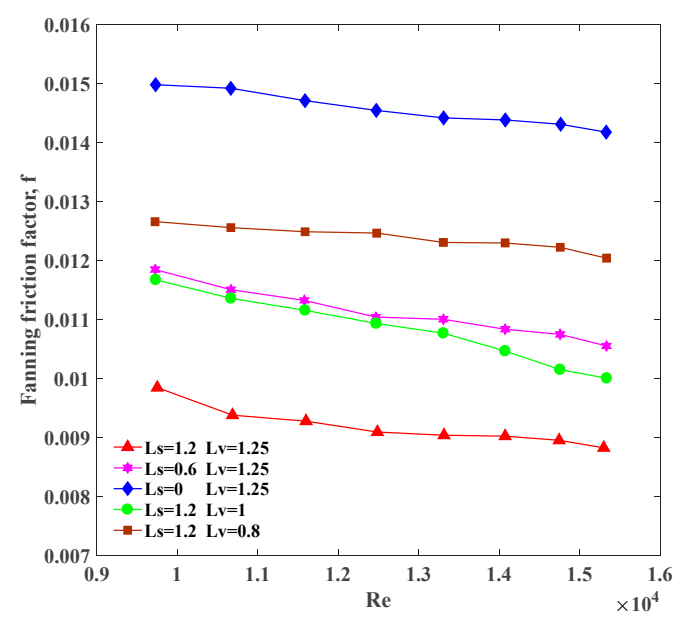

(b)

Figure 10. The overall pressure drop versus mass flux and overall Fanning friction factor versus Re for different fin arrangements: (a) overall pressure drop versus mass flux; (b) overall Fanning friction factor versus Re.

The PEC values for different fin arrangements are shown in Figure 11. The value of the PEC for the staggered channel geometry is higher compared with that of the base geometry of the parallel channel. The PEC values for the channel geometries of $L_{S}=1.2 \mathrm{~mm}$, $\mathrm{L}_{\mathrm{V}}=1.25 \mathrm{~mm}$ and $\mathrm{L}_{\mathrm{s}}=1.2 \mathrm{~mm}, \mathrm{~L}_{\mathrm{v}}=0.8 \mathrm{~mm}$ decrease with increasing Re, but the channel geometries of $\mathrm{L}_{\mathrm{s}}=0.6 \mathrm{~mm}, \mathrm{~L}_{\mathrm{V}}=1.25 \mathrm{~mm}$ and $\mathrm{L}_{\mathrm{s}}=1.2 \mathrm{~mm}, \mathrm{~L}_{\mathrm{V}}=1 \mathrm{~mm}$ show the opposite trend. Under the same Re condition, when the $\mathrm{L}_{\mathrm{v}}$ increases from $0.8 \mathrm{~mm}$ to $1.25 \mathrm{~mm}$, the PEC value increases with the $\mathrm{L}_{\mathrm{v}}$ increasing. These results show that among all fin arrangements, the PEC average value of the staggered channel with $\mathrm{L}_{\mathrm{S}}=1.2 \mathrm{~mm}$ and $\mathrm{L}_{\mathrm{v}}=1.25 \mathrm{~mm}$ is the highest, which is $11.6 \%$ higher than that of the parallel channel. It could be deduced that the comprehensive heat transfer performance can be improved by properly increasing the staggered distance $\left(\mathrm{L}_{\mathrm{S}}\right)$ and vertical distance between the two rows of fins $\left(\mathrm{L}_{\mathrm{V}}\right)$.

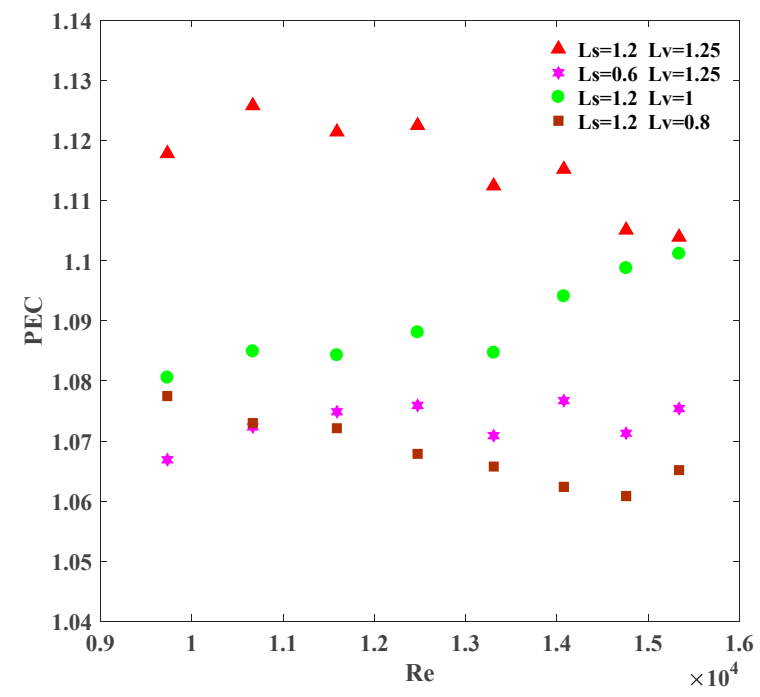

Figure 11. Performance evaluation criteria for different fin arrangements. 


\section{Conclusions}

The effects of different arrangements of airfoil fins characterized by staggered distance $\left(\mathrm{L}_{\mathrm{S}}\right)$ and transverse distance $\left(\mathrm{L}_{\mathrm{V}}\right)$ on the heat transfer and hydraulic resistance of supercritical nitrogen in the PCHE were studied in the present study. The local characteristics and the overall performance of the heat exchanger for different fin arrangements were analyzed. The major conclusions of this study can be summarized as follows:

1. When $L_{v}$ is constant, the velocity distribution tends to be stable gradually as the $L_{s}$ increases from $0 \mathrm{~mm}$ to $1.2 \mathrm{~mm}$. Since the fin structure is wide head and narrow tail, it is easier to form a streamline when the fins are staggered. As the tail of the fin is narrow, there is nearly no vortex at the tail of the fin. In the case of completely staggered airfoil fins $\left(\mathrm{L}_{\mathrm{s}}=1.2 \mathrm{~mm}\right)$, the velocity improvement and uniform distribution can be achieved when $L_{s}$ is the minimum value, i.e., $0.8 \mathrm{~mm}$. The increasing trend of the velocity along the channel is similar for different fin arrangements and this increasing trend becomes steeper along the channel. In addition, when the $\mathrm{L}_{\mathrm{s}}$ increases from $0 \mathrm{~mm}$ to $1.2 \mathrm{~mm}$, the change in pressure becomes lower under the condition of constant $\mathrm{L}_{\mathrm{v}}$. At the same staggered distance $\left(\mathrm{L}_{\mathrm{s}}=1.2 \mathrm{~mm}\right)$, reducing the vertical distance between two rows of fins can lead to an increased pressure reduction.

2. When the $\mathrm{L}_{\mathrm{v}}$ remains constant, the convective heat transfer performance is enhanced by decreasing the value of $L_{s}$. In addition, when $L_{s}$ is at a constant value of $1.2 \mathrm{~mm}$, the vertical distance of $\mathrm{L}_{\mathrm{V}}=0.8 \mathrm{~mm}$ has a stronger convective heat transfer performance than that at $\mathrm{L}_{\mathrm{v}}=1 \mathrm{~mm}$ and $\mathrm{L}_{\mathrm{v}}=1.25 \mathrm{~mm}$. Hence, appropriate reductions in $\mathrm{L}_{\mathrm{S}}$ and $\mathrm{L}_{\mathrm{V}}$ are more suitable for improving the convective heat transfer of the PCHE.

3. At the same vertical distance $\left(\mathrm{L}_{\mathrm{V}}=1.25 \mathrm{~mm}\right)$, the pressure drop decreases with the increase in $\mathrm{L}_{\mathrm{s}}$. Therefore, when $\mathrm{L}_{\mathrm{s}}=1.2 \mathrm{~mm}$, the average pressure drop is the minimum, only $56.6 \%$ of the parallel arrangement. For the same $L_{s}$ of $1.2 \mathrm{~mm}$, the pressure loss decreases by $34.9 \%$ on average as the vertical distance increases from $0.8 \mathrm{~mm}$ to $1.25 \mathrm{~mm}$. Therefore, appropriate increases in $\mathrm{L}_{\mathrm{s}}$ and $\mathrm{L}_{\mathrm{V}}$ can reduce the pressure loss.

4. Among all fin arrangements, the PEC average value of the staggered channel with $\mathrm{L}_{\mathrm{s}}=1.2 \mathrm{~mm}$ and $\mathrm{L}_{\mathrm{v}}=1.25 \mathrm{~mm}$ is the highest, which is $11.6 \%$ higher than that of the parallel channel, especially for a smaller value of Re. The comprehensive heat transfer performance can be improved by increasing the $\mathrm{L}_{\mathrm{s}}$ and $\mathrm{L}_{\mathrm{v}}$.

Author Contributions: Conceptualization, S.Y. and Z.Z.; visualization, formal analysis and writing -original draft preparation, S.Y., Y.Z. and Z.Z.; methodology, validation and data curation, S.Y., Y.Z., Z.C. and M.Y. All authors have read and agreed to the published version of the manuscript.

Funding: This research was funded by Jiangsu marine and fishery science and technology innovation and extension project, grant number HY2017-8, and Zhenjiang funds for the key research and development project, grant number GY2016002-1.

Institutional Review Board Statement: Not applicable.

Conflicts of Interest: The authors declare no conflict of interest.

\section{Nomenclature}

A area

$\mathrm{C}_{\mathrm{p}} \quad$ specific heat

$\mathrm{D}_{\mathrm{h}} \quad$ hydraulic diameter

f Fanning friction factor

$\mathrm{h} \quad$ convective heat transfer coefficient

L length of channel

$\mathrm{m} \quad$ mass flow rate

$\mathrm{Nu} \quad$ Nusselt number 


$\begin{array}{ll}\text { P } & \text { pressure drop } \\ \text { PCHE } & \text { Printed Circuit Heat Exchanger } \\ \text { PEC } & \text { Performance Evaluation Criteria } \\ \text { Pr } & \text { Prandtl number } \\ \text { q } & \text { heat flux } \\ \text { Re } & \text { Reynolds number } \\ \text { S } & \text { surface area } \\ \text { SST } & \text { Shear Stress Transport } \\ \text { T } & \text { temperature } \\ \text { V } & \text { volume } \\ \text { Greek letters } & \\ \rho & \text { density } \\ \lambda & \text { thermal conductivity } \\ \mu & \text { dynamic viscosity } \\ v & \text { velocity } \\ \text { Subscripts } & \\ \text { w } & \text { wall } \\ \text { in } & \text { inlet } \\ \text { out } & \text { outlet } \\ \text { b } & \text { bulk } \\ \text { h } & \text { hydraulic } \\ l & \text { liquid } \\ \text { a } & \text { airfoil fin } \\ \text { c } & \text { chord length }\end{array}$

\section{References}

1. Bartel, N.; Chen, M.; Utgikar, V.P.; Sun, X.; Kim, I.H.; Christensen, R.; Sabharwall, P. Comparative analysis of compact heat exchangers for application as the intermediate heat exchanger for advanced nuclear reactors. Ann. Nucl. Energy. 2015, 83, 143-149. [CrossRef]

2. Hesselgreaves, J.E. The impact of compact heat exchangers on refrigeration technology and CFC replacement. In Proceedings of the International Refrigeration and Air Conditioning Conference, West Lafayette, IN, USA, 25-28 July 1990.

3. Pra, F.; Tochon, P.; Mauget, C.; Fokkens, J.; Willemsen, S. Promising designs of compact heat exchangers for modular HTRs using the Brayton cycle. Nucl. Eng. Des. 2008, 238, 3160-3173. [CrossRef]

4. Chen, L.; Zhang, X.R.; Okajima, J.; Maruyama, S. Numerical investigation of near-critical fluid convective flow mixing in micro-channels. Chem. Eng. Sci. 2013, 97, 67-80. [CrossRef]

5. Chu, W.X.; Li, X.H.; Ma, T.; Chen, Y.T.; Wang, Q.W. Experimental investigation on $\mathrm{SCO}_{2}$-water heat transfer characteristics in a printed circuit heat exchanger with straight channels. Int. J. Heat Mass Tran. 2017, 113, 184-194. [CrossRef]

6. Zhao, Z.C.; Zhang, X.; Zhao, K.; Jiang, P.P.; Chen, Y.P. Numerical investigation on heat transfer and flow characteristics of supercritical nitrogen in a straight channel of printed circuit heat exchanger. Appl. Therm. Eng. 2017, 126, 717-729. [CrossRef]

7. Nikitin, K.; Kato, Y.; Ngo, L. Printed circuit heat exchanger thermal-hydraulic performance in supercritical $\mathrm{CO}_{2}$ experimental loop. Int. J. Refrig. 2006, 29, 807-814. [CrossRef]

8. Lee, S.M.; Kim, Y.K. Multi-objective optimization of arc-shaped ribs in the channels of a printed circuit heat exchanger. Int. J. Therm. Sci. 2015, 94, 1-8. [CrossRef]

9. Tsuzuki, N.; Kato, Y.; Ishiduka, T. High performance printed circuit heat exchanger. Appl. Therm. Eng. 2007, 27, 1702-1707. [CrossRef]

10. Lee, S.M.; Kim, K.Y. Optimization of zigzag flow channels of a printed circuit heat exchanger for nuclear power plant application. J. Nucl. Sci. Technol. 2012, 49, 343-351. [CrossRef]

11. Ngo, T.L.; Kato, Y.; Nikitin, K.; Tsuzuki, N. New printed circuit heat exchanger with S-shaped fins for hot water supplier. Exp. Therm. Fluid Sci. 2006, 30, 811-819. [CrossRef]

12. Ngo, T.L.; Kato, Y.; Nikitin, K.; Ishizuka, T. Heat transfer and pressure drop correlations of microchannel heat exchangers with S-shaped and zigzag fins for carbon dioxide cycles. Exp. Therm. Fluid Sci. 2007, 32, 560-570. [CrossRef]

13. Xu, X.Y.; Ma, T.; Li, L.; Zeng, M.; Chen, Y.T.; Huang, Y.P.; Wang, Q.W. Optimization of fin arrangement and channel configuration in an airfoil fin PCHE for supercritical $\mathrm{CO}_{2}$ cycle. Appl. Therm. Eng. 2014, 70, 867-875. [CrossRef]

14. Kim, T.H.; Kwon, J.G.; Yoon, S.H.; Park, H.S.; Kim, M.H.; Cha, J.E. Numerical analysis of airfoil shaped fin performance in printed circuit heat exchanger in a supercritical carbon dioxide power cycle. Nucl. Eng. Des. 2015, 288, 110-118. [CrossRef]

15. Chen, F.; Zhang, L.S.; Huai, X.L.; Li, J.F.; Zhang, H.; Liu, Z.G. Comprehensive performance comparison of airfoil fin PCHEs with NACA 00XX series airfoil. Nucl. Eng. Des. 2017, 315, 42-50. [CrossRef]

16. Kwon, J.G.; Kim, T.H.; Park, H.S.; Cha, J.E.; Kim, M.H. Optimization of airfoil-type PCHE for the recuperator of small scale brayton cycle by cost-based objective function. Appl. Therm. Eng. 2016, 298, 192-200. [CrossRef] 
17. Kim, D.E.; Kim, M.H.; Cha, J.E.; Kim, S.O. Numerical investigation on thermal hydraulic performance of new printed circuit heat exchanger model. Nucl. Eng. Des. 2008, 238, 3269-3276. [CrossRef]

18. Ma, T.; Xin, F.; Li, L.; Xu, X.Y.; Chen, Y.T.; Wang, Q.W. Effect of fin-end wall fillet on thermal hydraulic performance of airfoil printed circuit heat exchanger. Appl. Therm. Eng. 2015, 89, 1087-1095. [CrossRef]

19. Popova, D.; Fikiin, K.; Stankov, B.; Alvarez, G.; Youbi-Idrissi, M.; Damas, A.; Evans, J.; Brown, T. Cryogenic heat exchangers for process cooling and renewable energy storage: A review. Appl. Therm. Eng. 2019, 153, 275-290. [CrossRef]

20. Zhao, Z.C.; Chen, X.D.; Zhang, X.; Ma, X.L.; Yang, S. Experimental and numerical study on thermal-hydraulic performance of printed circuit heat exchanger for liquefied gas vaporization. Energy Sci. Eng. 2020, 8, 426-440. [CrossRef]

21. Zhao, Z.C.; Zhang, Y.R.; Chen, X.D.; Ma, X.L.; Yang, S.; Li, S.L. A numerical study on condensation flow and heat transfer of refrigerant in minichannels of printed circuit heat exchanger. Int. J. Refrig. Rev. Int. Froid. 2019, 102, 96-111. [CrossRef]

22. Zhao, Z.C.; Zhou, Y.M.; Ma, X.L.; Chen, X.D.; Li, S.L.; Yang, S. Numerical Study on Thermal Hydraulic Performance of Supercritical LNG in Zigzag-Type Channel PCHEs. Energies 2019, 12, 548. [CrossRef]

23. Zhao, Z.C.; Zhao, K.; Jia, D.D.; Jiang, P.P.; Shen, R.D. Numerical Investigation on the Flow and Heat Transfer Characteristics of Supercritical Liquefied Natural Gas in an Airfoil Fin Printed Circuit Heat Exchanger. Energies 2017, 10, 1828. [CrossRef]

24. Zhao, Z.C.; Zhang, Y.; Chen, X.D.; Ma, X.L.; Yang, S.; Li, S.L. Experimental and numerical investigation of thermal-hydraulic performance of supercritical nitrogen in airfoil fin printed circuit heat exchanger. Appl. Therm. Eng. 2020, 168, 114829. [CrossRef]

25. ANSYS CFX-12.1 Solver Theory Guide, ANSYS, Inc. 2009. Available online: http:/ /www.ansys.com/ (accessed on 23 March 2021).

26. Yang, Z.D.; Wang, S.W.; Li, Y. Experimental and numerical analysis of heat transfer to water at supercritical pressures. Int. J. Heat Mass Tran. 2017, 108, 1676-1688. [CrossRef]

27. Li, Z.H.; Wu, Y.X.; Lu, J.F.; Zhang, D.L.; Zhang, H. Heat transfer to supercritical water in circular tubes with circumferentially non-uniform heating. Appl. Therm. Eng. 2014, 70, 190-200. [CrossRef]

28. Wen, Q.L.; Gu, H.Y. Numerical investigation of acceleration effect on heat transfer deterioration phenomenon in supercritical water. Prog. Nucl. Energy. 2011, 53, 480-486. [CrossRef]

29. Xu, X.Y.; Wang, Q.W.; Li, L.; Ekkad, S.V.; Ma, T. Thermal-hydraulic performance of different discontinuous fins used in a printed circuit heat exchanger for supercritical $\mathrm{CO}_{2}$. Numer. Heat Transf. Part A Appl. 2015, 68, 1067-1086. [CrossRef]

30. Taylor, N.B.; Kuyatt, C.E. Guideliness for Evaluating and Expressing the Uncertainty of NIST Measurement Results; NIST Technical Note 1297; National Institute of Standards and Technology: Gaithersburg, MD, USA, 1994.

31. Figley, J.; Sun, X.D.; Mylavarapu, S.K.; Hajek, B. Numerical study on thermal hydraulic performance of a printed circuit heat exchanger. Prog. Nucl. Energy. 2013, 66, 89-96. [CrossRef]

32. Webb, R.L.; Kim, N.H. Algebraic Formulation of the PEC. In Principles of Enhanced Heat Transfer, 2nd ed.; Taylor \& Francis Group: Milton Park, UK, 2005; pp. 1-816. 